\title{
ATAHUALPA YUPANQUI: LA PALABRA \\ DESDE EL SILENCIO
}

Marcela Gloria Romano ${ }^{1}$

Piedra Sola, de Atahualpa Yupanqui, publicado por primera vez en 1940, con algunos poemas reeditados y levemente modificados en libros posteriores como Guitarra, de 1960, y El Payador Perseguido, de 1972, es un breve pocmario cuyo subtítulo, Poemas del Cerro, ya advierte sobre la contextualización cultural y expresiva que confirmará posteriormente el libro: el noroeste andino es, en Piedra Sola, el paisaje temático dominante, desplegado a partir de alusiones a elementos de la naturaleza, tipos humanos regionales, preocupaciones caracteristicas. Asimismo, la prática poética recupera, en gran parte del corpus, una forma de escritura, oral, tradicional -la de la copla-, actualizada en su nivel de lengua propio, estilización ${ }^{2}$ que permite encuadrar el texto dentro del sistema literario de "proyección folklórica" ${ }^{3}$.

1 Universidad Nacional de Mar del Plata

2 Según Bajtin y su dibujo de los modos de intertextualidad, "en el caso de que la palabra del autor se presente de modo que se precisa su caracterizzción o tipicidad en relación con una persona determinada, con una cienta posición social, con una manera artistia especial, estamos frente a una estilización, ya sea ésta una estilización literaria habitual, ya un discurso oral estilizado". Cfr. Mikail Bajtin, La poética de Dostoievsky. México: Fondo de Cultura Económica, 1981: 260.

3 Todavia nos parece sumamente esclarecedorala distinción que Augusto Raúl Cortazar realiza entre "folklore literario" y "literautra folklórica", concedićndole a ćsta última la cualidad de constituirse en "proyección" del primero. Y especifica sus rasgos: "a) Son expresiones de fenómenos folklóricos; b) producidas fuera de su ámbito geográfico y cultural, c) por obra de personas determinadas o determinables, d) que se inspiran en la realidad folklórica, e) cuyo estilo, formas, ambiente o carácter trasuntan y reclaboran en sus obras f) 
Nuestro trabajo se detendrá especificamente en la confirmación paulatina de un presupuesto: existe en Piedra Sola la constitución de una poética peculiar, una poética desde el silencio la cual, dibujada a lo largo del poemario por la misma escritura, remite referencialmente a una instancia antropológica que la contiene: el mundo indigena de los Andes, su filiación armónica con el medio, su natureza esencialmente contemplativa.

Ya la dedicatoria, que junto con el título y el subtitulo, diseñan el marco paratextual ${ }^{4}$ de los poemas, esboza un modo particular de poetizar:

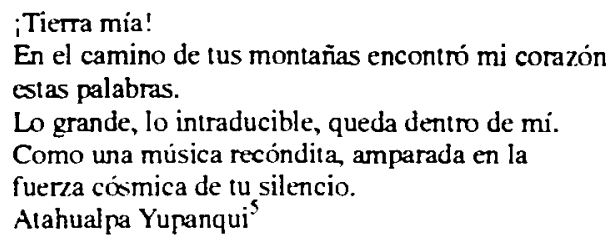

El pretexto prepara, como mencionamos, la recipción del corpus total, y determina, inicialmente, los sujetos escriturales predominantes y la relación de homología que entre sí establecem. La dedicatoria comienza con una exclamación apelativa - Tierra mia! - que tiene como destinatario un "tú" especifico: el paisaje de montaña, aqui, como en muchos poemas del libro, humanizado, convertido en sujeto potencialmente dialógico. Un "tú" caracterizado, según vemos hacia el final, por "la fuerza cósmica del tu silencio", rasgo que plantea, conceptualmente, una dimensión transcendentalista que intentaremos delimitar en su diseño poético. El emisor, por us parte, aparece construido como "hablante-autor" de los poemas que siguen, homologándose con el sujeto autorial: "Atahualpa Yupanqui", quien firma la dedicatoria. Este "yo" revela, ya en el pretexto, su concepción acerca de la práctica poética: en primer lugar, encuentra sus palabras con el "corazón"(poesia entonces, ligada a la vida); luego, y esto interesa especialmente a nuestra hipótesis, agrega que "lo grande, lo intraducible, queda

destinadas al publico general, preferentemente urbano g) al cual se trasmiten por medios técnicos e institucionalizados. propios de cada civilización y de cada época". Cfr. Augusto Raul Cortazar, Folklore y litemtura. Bs.As.: Eudeba, 1964: 13.

4 Genette llama de este modo a los materiales textuales que rodean el cuerpo textual central: titulo, subtitulos, prefacio, advertencias, etc. y considera su ingerencia como "uno de los lugares privilegiados de la dimensión pragmatica de la obra, es decidir, de su acción sohre el lector". Dfr. Gerard Genetle, Palimpsestos. La literatura en segundo grado. Madrid: Tauns. 1990: 11-12.

5 Cfr. Atahualpa Yupanqui, Piedra Sola. Poemas del Cerno (1940). Bs. As.: Siglo Veinte, 1979: 5. 
dentro de mí. Como una música recóndita...". Lo esencialmente poético es, para el hablante, aquello que no se dice, el silencio, similar al de la montaña y sus secretos interiores. Lo "intraducible" plantea, entonces, la idea de la insuficiencia de la palabra humana para revelar completamente la realidad, al tiempo que establece, dentro de ésta, un nivel existencial de trascendencia asociado con el universo mítico andino 6 .

El poema que da nombre al libro, Piedra Sola, instala, desde el principio, la identidad hombre-naturaleza. Si bien este texto no alude directamente al problema que nos ocupa, si ofrece una muestra de la relación yo-tú (naturaleza) en permanente situación de interlocución, al tiempo que retrata un elemento de mundo telúrico caracterizado, justamente, por la fuerza interior de su silencio, frente a un destino poco feliz, paradigma de la vida humana:

\author{
Para junto al camino \\ Piedra Sola, \\ ¿qué vientos te derribaron \\ de la cumbre? \\ ¡Cómo vives tu destino! \\ Piedra Sola, \\ Grandeza que no ha quebrado \\ tu derrumbe...
}

(Yupanqui: 7)

La figura de la piedra vinculada simbólicamente a la del hombre se presenta reiteradamente a lo largo del poemario. En muchos de ellos, la piedra es el correlato natural de los duros "trabajos" impuestos por una vida marginal, alusión que impone en el texto, aun cuando tangencialmente, una voz de denuncia. Así, en Cumbreña, el hablante se desplaza hacia un "yo" femenino que, desde su propio nivel de lengua, emite su queja:

Trabajar con mala paga
por culpa de mi destino.
Toditos quieren golpearme
con las piedras del camino...

(Yupanqui: 72)

6 Importa destacar la densidad semiótica aportada al hablante escritural por el hablante real, Héctor Chavero, mediante su figura artistica, Atahualpa Yupanqui. El constructo "espectacular" del cantante y compsitor condiciona la recepción del texto a través de su seudónimo, su imagen física, su vestimenta, el estatuto casi mítico que la opinión le ha conferido. Estos códigos extratextuales lo enlazan, naturalmente, con el sujeto del enunciado, cuya constitución resulta asi notablemente enriquecida. 
Frente a una existencia signada por el dolor y el esfuerzo, el universo interior, inalterable. Ambos costados de la realidad humana se cifran en Piedra y cielo mediante una economía de recursos -pura sustantivación, versos de arte menor, lexías de tono sentencioso- que señala el esfurezo de sintesis y desnudez expresivas solidarias con la poética conceptualmente buscada:

¡ Mi vida! Piedras afueta, cielos adentro...

(Yupanqui: 69) ${ }^{7}$

Pero es en el poema Piedras donde este elemento telúrico se revela como correlato natural del poderoso silencio del espíritu:

No digo que tengan voz

ni que se digan palabras;

nasiones el silencio

dice las cosas más claras...

; Algo se dicen las piedras!

A mi no me engaña el alma.

Temblor, sombra o qué sé yo...

Mesmo que si conversaran...

¡ Malhaya! Pudiera un día vivir asi: sin palabras...

(Yupanqui: $47-48$ )

El discurso regionalizado, a cargo de un hablante contextualizable culturalmente, acusa una sencillez absolutamente ligada a la ascesis poética inicialmente planteada. Lenguaje perfectamente decodificable, con una fuerte presencia del sujeto emisor, cuyo saber se genera a partir de un conocimiento intuitivo: "A mi no me engaña el alma". Detrás de esta transparencia comunicativa, se esconde, sin embargo, una cuidada retórica de la elipsis: insistencia en el uso de deicticos con valor de indefinición ("algún algo", "algo"), lexías perifrásticas ("o que sé yo"), sustantivos que remiten a una semántica de ambigüedad ("Temblor, sombra...), sentencias lecónicas ("Ocasiones el silencio/dice las cosas más claras..."), utilización de puntos suspensivos. Todas estas estrategias, relacionadas algunas de ellas con los modelos retóricos de la poesía mistica, conforman un camino poético

7 Cr. también los poemas "Canción de Cuna". "El quenero" y "La quena rota". Cfr. Atahualpa Yupanqui, ibidem: 22,33 y 49 respectivamente. 
cuya meta es la final ausencia de palabras, el silencio pleno de significados, la nada textual sumergida en un estado de contemplación absoluta: "Malhaya, pudiera un dia/ vivir así: sin palabras...".

Este programa no surge, por su parte, como una estética aislada. La práctica poética es, en este sistema cultural, una práctica religiosa, convocante de lo sagrado: la ascesis poética pone en estrecho contacto la voz del emisor con la voz universal, cósmica, en la que éste se instaura dialógicamente desde su aspiración al silencio. La concepción del hombre como microcosmos del orden universal se encuentra cifrada en Copla, donde el urabajo de despojamiento expresivo llega a su máxima porfundización en este libro:

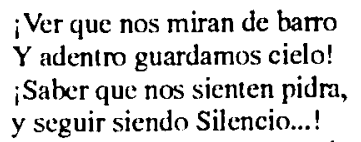

(Yupanqui: 11)

Esta copla se integra métricamente a las formas de la poesia hispana tradicional y, desde una fisonomia popular, se acerca en el nivel conceptual a preocupaciones de raiz metafísica. La exasperación del afản de brevedad se traduce en la clección de una única estrofa $(y$ de arte menor, que restringe todo posible despliegue retórico y grandilocuente) en la contitución del poema. Asimismo, su montaje formal acusa nuevamente una filiación con la escritura elíptica. La copla se divide en dos zonas sintácticas unimembres, a la vez subdivididas en pares scmánticamente antitéticos, girando alrededor de "barro-cielo" y "piedra-Silencio". La utilización de verboides infinitovos como núcleos de estos sintagmas despoja la "anécdota" lírica de subjetividad y temporalidad para conferirle un matiz sentencioso de naturaleza generalizadora. Al mísmo tiempo, los pares de sustantivos enfrentados se presentan desnudos de toda adjetivación, concentrando en su significado simbólico toda la fuerza semántica de la copla. La especilicidad del "silencio" al que se alude al final está marcada en el texto por la mayúscula, de función sacralizadora, para indicar el contraste con la mudez aparentemente estéril de la "piedra". Hay a la vez una homologación entre los primeros términos de las antitesis, "barro" _"piedras" (contingencia) y "cielo"_"Silencio" (ser), alrededor de la cual se plantea el motivo fundamental del poema: la apariencia humana contingente y su verdadeiro destino de eternidad, correlato del Silencio armónico de la naturaleza. 
Pero en Piedra Sola no sólo la "piedra"remite simbólicamente al "silencio" universal. Con menor aunque eficaz protagonismo, también el agu $a^{8}$ es cifra de este destino trascendente. El poema Agüita del pedregal (título que asocia, no arbitrariamente, ambos elementos) diseña, paradigmáticamente, el perfil de esta voz poética en diálogo con la voz. universal:

\author{
Ruidosos corren los rios \\ deshaciendo el arenal; \\ aguas que corten furiosas \\ se enturbian cada vez más. \\ ¿Que eso nunca te confunda, \\ agūita del manantia!! \\ Sabe que tambien hay fuerzas \\ en tu callado viajar... \\ En mucho nos parecemos, \\ agüita del pedregal..."
}

Nuevamente aqui, como en el caso de la piedra, se elige un clemento "menor", insignificante, de la naturaleza, para exaltar su fuerza interior. En este ejemplo especifico, el hablante se iguala al "tú" (agua de manantial), también humanizado, rescatando de ella su modo de ser particular: la humanidad, el silencio, la pequeñez, la transparencia, enfrentadas con el protagonismo violento y turbio de los "rios".

Estos sentidos remiten simbólicamente a dos modelos de expresión, a dos poéticas: aquella que despliega su fuerza "ruidosa" y declamatoria, y la escogida por el hablante, pobre en caudal, casi muda, aparentemente estéril. Una poética de la restricción, de frutos apenas visibles, pero que esconde, como el agua del manantial, la fuerza interior de la tierra, que permanece, latente, en la palabra no dicha.

Esta mirada sobre la estética de Yupanqui resulta incompleta en la medida en que nos hemos restringido a un sólo libro, y, dentro de éste, a unos pocos poemas. Sin embargo, consideramos que nuestro breve rastreo ha servido para establecer, al menos superficialmente, uno de los rasgos

\footnotetext{
8 Cfr. la presencia de este motivo en los poemas "Noche en el rio", "Candonga", "Siesta", "Yacochay"(Ibidem: 42, 54-55. 56-57 y 88 respectivamente).

9 La versión del poema aqui escogida es la ultima, publicada dentro de una antologia que acompaño a El payador perseguido Bs. As.: Siglo Veinte. 1972: 75. Alli se modifica la versión inicial en la ültima estrofa, asi publicada (Dfr, Piedra Sola: 9-10)

i En algo nos parecemos.

agüita del pedregal...!
} 
escriturales más sobresalientes en la producción poética y cancioneril de Atahualpa: su vinculación profunda con las formas poéticas populares, el encuentro de las mismas con los grandes temas universales, la contextualización de éstos en un sistema cultural específico. Un sistema cultural -el indigena de los Andes- que funda, a su vez, una particular concepción de lo sagrado: la del hombre en armonía con la naturaleza, la del reacio silencio de esa naturaleza y de sus hombres como la más perfecta de todas las palabras. A esta poética tiende, en un esfuerzo calculado de sencillez y despojamiento, que abreva también de la sabiduria anónima popular, la voz de Yupanqui. 